


\title{
Grundzüge der physischen Erdkunde
}

\author{
Von
}

\author{
Dr. Alexander Supan \\ o. Prof. der Geographie an der Schlesischen Friedrich-Willuelms-Lniversität \\ in Breslau \\ Sechste umgearbeitete und verbesserte Auflage \\ 982 Seiten mit 277 Textabbildungen und 20 farbigen Tafeln \\ Groß-Oktav. Geheftet M. 19.-, gebunden M. 23.-
}

Die neue Auflage des vortrefflichen Lehrbuches ist mit allen Vorzügen der früheren Auflagen ausgestattet. Die Ausstattung des Werkes ist wiederum sehr gut. Möge es recht vielen als sicherer Führer dienen. Geogr. Zeitschrift.

Man sagt sicher nicht $z u$ viel, wenn man dieses treffliche Werk in seiner jetzigen Gestalt als das beste Lehrbuch der physischen Erdkunde bezeichnet (Dr. Jos. Reindl). Münchener Allgem. Zeitung.

Ein Meisterwerk, in welchem die Probleme des Gesamtgebietes der physischen Geographie selbständig und mit eindringender Kenntnis der Gegenstände behandelt sind.

Ferd. von Richthofen.

Sven Hedin erzählte einmal, daß3 unter den wenigen Büchern, die er in die Wildnis Asiens mitnahm, auch Supans Grundzüge der physischen Erdkunde gewesen sei. Man kann das verstehen. Es gibt kein Buch dieser Art mehr, das neben wissenschaftlicher Gründlichkeit, neben einer solchen Menge von Material, neben einer solchen Selbständigkeit in der Auffassung so viel Klarheit und so viel Künstlerisches in der Darstellung besitzt. Rit. Rundschm.

\section{Leitlinien \\ der allgemeinen politischen Geographie}

\author{
Von
}

\section{Dr. Alexander Supan}

o. Prof. der Geographie an der Schlesischen Friedrich-Wilhelms-Universität in Bresiau

Mit 3 Kärtchen im Text

GroB-Oktav. Geheftet M. 5.-, gebunden M. 7.-

Gegenüber der allzu einseitigen Betonung der physischen Geographie ist es ein unabweisbares Bedürfnis unserer Zeit, der politischen Seite wieder erhöhte Beachtung zu schenken. Der Staat soll in den Mittelpunkt der geographischen Betrachtung gerückt werden. Aber nicht in der Weise der Schulbücher und alten Kompendien. Es muß zunächst ein festgefügtes System der allgemeinen politischen Geographie geschaffen werden. RatzeIs Werk reicht nach Ansicht des Verfassers dafür nicht aus....

Das vorliegende Werk des berühmten Gelehrten wird jedem Gebildeten gute Dienste leisten. Bamberger Tageblatt.

Gesamtteuerung8zuschlag bis auf weiteres $25 \%$

Verlag von Veit \& Comp. in Leipzig, Marienstraße 18 


\title{
Die Vorherbestimmung des Wetters.
}

\author{
Antrittsvorlesung, \\ gehalten am 20. Juli 1918 in der \\ Aula der Universität Leipzig \\ von

\section{ROBERT WENGER,} \\ Dr. phil. nat., a.o. Prof. der Geophysik.
}
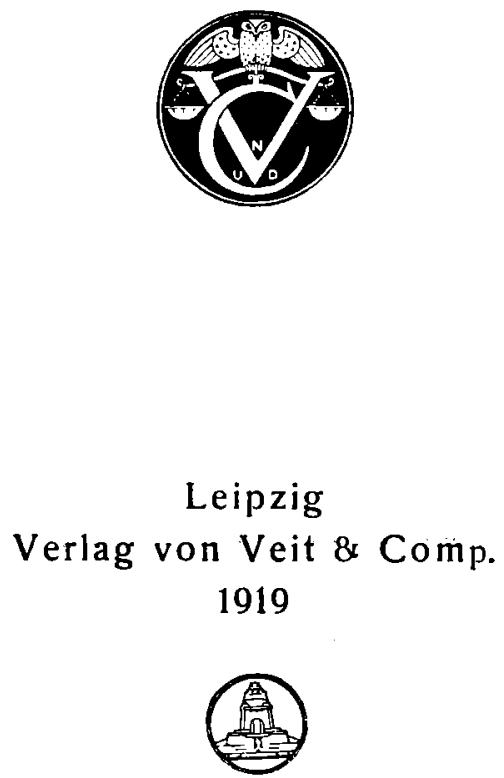
Druck von Metzger \& Wittig in Leipzig. 